\title{
Perubahan Tingkat Pendapatan Petani Pemilik Lahan Setelah Adanya Alih Fungsi Lahan di Kecamatan Ciparay
}

\author{
Ikbal Kamiludin Gunawan*, Ivan Chofyan \\ Jurusan Perencanaan Wilayah dan Kota, Universutas Islam Bandung, \\ Indonesia \\ *ikbalkamiluding@gmail.com, chofyanivan@gmail.com
}

\begin{abstract}
Ciparay Sub-District is one of the areas that have changed the function of agricultural land to nonagricultural, this is due to its strategic geographical location that makes investors race to get the land in the area. The area of agricultural land in Ciparay sub-district each year has a significant change in which Ciparay subdistrict is one of the sub-districts that has ample agricultural land. Area of Ciparay subdistrict $\pm 46,175.6$ $\mathrm{Ha}$, with land area planting rice $\pm 7,390$ ha in the year 2014 or average of land change amounted to $6.9 \%$ per year. The purpose of this research is to cover the impact of land function on land owner farmers Income level quantitative analysis used is an average difference test analysis with data collection techniques by distributing the questionnaire to 29 respondents. Based on the results of the study can be concluded that by the existence of land function has an impact on the farmers in Ciparay sub-district that the income of the owners of farmers, smaller than before the land function. Because seen from the results of analysis of average difference obtained the value of $\mathrm{T}$ count $<\mathrm{T}$ table which means $\mathrm{H} 0$ on reject and $\mathrm{H} 1$ accepted.
\end{abstract}

Keywords: Farmland, land-over function, income

Abstrak. Kecamatan Ciparay merupakan salah satu daerah yang mengalami perubahan fungsi lahan pertanian ke non pertanian, hal ini dikarenakan letak geografisnya yang strategis yang membuat para investor berlomba - lomba untuk mendapatkan lahan yang ada di kawasan tersebut. Luas lahan pertanian di Kecamatan Ciparay setiap tahunnya mengalami perubahan yang cukup signifikan dimana Kecamatan Ciparay merupakan salah satu kecamatan yang memiliki lahan pertanian yang cukup luas. Luas Kecamatan Ciparay \pm 46.175,6 Ha, dengan luas lahan tanam padi sawah \pm 7.390 ha pada tahun 2014 atau rata - rata perubahan lahan sebesar $6,9 \%$ per tahun. Tujuan penelitian ini untuk melihat dampak alih fungsi lahan terhadap tingkat pendapatan petani pemilik lahan Analisis kuantitatif yang digunakan adalah analisis uji beda rata-rata dengan teknik pengumpulan data dengan cara membagikan kuisioner kepada 29 orang responden. Berdasarkan hasil penelitian dapat ditarik kesimpulan bahwa dengan adanya alih fungsi lahan memberikan dampak terhadap para petani yang ada di Kecamatan Ciparay bahwa pendapatan para petani pemilik, lebih kecil jika dibandingkan dengan sebelum adanya alih fungsi lahan. Karena dilihat dari hasil analisis uji beda rata-rata didapat nilai $\mathrm{T}$ hitung < T tabel yang artinya $\mathrm{H}_{0}$ di tolak dan $\mathrm{H}_{1}$ diterima.

Kata Kunci: Lahan pertanian, alih fungsi lahan, pendapatan. 


\section{A. Pendahuluan}

Lahan merupakan sumberdaya yang sangat penting dalam bidang pertanian khusunya bagi petani dalam melakukan kegiatan pertanian. Lahan yang luas akan semakin memperbesar harapan petani untuk mendapatkan hidup yang layak.

Seiring dengan meningkatnya jumlah penduduk, keberadaan lahan terutama lahan untuk pertanian menjadi semakin terancam dikarenakan desakan kebutuhan akan lahan yang lebih banyak, sementara jumlah lahan yang tersedia tidak pernah bertambah. Sektor pertanian yang dulunya menjadi penyumbang devisa terbesar, namun saat ini semakin tertinggal dari sektor yang lainnya. Kesejahteraan masyarakat yang tidak semakin membaik menjadi pendorong terjadinya konversi lahan pertanian.

Konversi lahan pertanian merupakan pengalihfungsian lahan pertanian dan segala pemanfaatannya menjadi non pertanian. Implikasi konversi lahan ini terhadap para petani adalah berubahnya struktur agraria dalam komunitas petani tersebut. Hal ini dapat dilihat jika setelah konversi lahan dengan kurun waktu yang cukup lama. Pemilik lahan akan terpengaruh untuk menjual atau mengalihfungsikan lahannya karena harga akan semakin melonjak khususnya di daerah yang berdekatan dengan pusat-pusat kegiatan masyarakat.

Menurut Irawan dan Friyanto (2005) dalam Januar Fajar (2016), alih fungsi lahan pertanian pada tingkat mikro dapat dilakukan oleh petani sendiri atau dilakukan pihak lain. Alih fungsi lahan yang dilakukan oleh pihak lain secara umum memiliki dampak yang lebih besar terhadap penurunan kapasitas produksi pangan, karena proses alih fungsi lahan tersebut biasanya mencakup hamparan lahan yang cukup luas, terutama ditunjukan untuk pembangunan kawasan perumahan

Fenomena yang selama ini terjadi menujukan bahwa pada dasarnya proses pembangunan pedesaan salah satunya ditandai oleh perkembangan dan perubahan dalam tatanan kehidupan masyarakat misalnya berubahnya sektor pertanian ke non pertanian. Nasoetion (1994) dalam A Hatu Rauf (2013), perubahan tersebut meliputi komponen maupun kondisi seperti (1) perubahan kondisi ekonomi petani (2) perubahan kondisi status dan peran sosial petani (3) perubahan kondisi penciptaan kesempatan kerja.

Kecamatan Ciparay merupakan salah satu daerah yang mengalami perubahan fungsi lahan pertanian ke non pertanian, hal ini dikarenakan letak geografisnya yang strategis yang membuat para investor berlomba - lomba untuk mendaptkan lahan yang ada di kawasan tersebut, selain itu adanya perubahan Tata Ruang Kecamatan Ciparay juga mempengaruhi konversi lahan pertanian yang ada. Luas lahan pertanian di Kecamatan Ciparay setiap tahunnya mengalami perubahan yang cukup besar dimana Kecamatan Ciparay merupakan salah satu kecamatan yang memiliki lahan pertanian yang cukup luas. Luas Kecamatan Ciparay \pm 46.175,6 Ha, dengan luas lahan tanam padi sawah \pm 7.390 ha pada tahun 2014 .

Menurunnya luas lahan pertanian di Kecamatan Ciparay karena dari data pada tahun 2014 sampai dengan 2017 mengalami penurunan yaitu dari 7.390 ha menjadi 6.878 ha terjadi penurunan luas lahan sebesar \pm 512 ha atau rata - rata perubahan lahan sebesar $6,9 \%$ per tahun. Dengan pertumbuhan ekonomi yang semakin meningkat yang terjadi di Kecamatan Ciparay ini menuntut adanya pembangunan berbagai infrastruktur sehingga permintaan akan lahan yang ada menjadi cukup besar dan menyebabkan banyak lahan pertanian yang beralih fungsi guna memenuhi permintaan tersebut.

Alih fungsi lahan di Kecamatan Ciparay sebagian besar dijadikan sebagai kawasan komersial seperti perumahan Pelangi Residence yang terletak di Desa Bumi Wangi, perumahan Permata Regency, pertokoan, cafe dan lain - lain. Perubahan menjadi kawasan komersial tersebut untuk mendatangkan keuntungan yang lebih banyak bagi para investor khususnya. Namun demikian, disisi lain dampak yang muncul dari alih fungsi lahan tersebut, salah satu perubahan penggunaan lahan tersebut adalah faktor ekonomi bagi petani. 


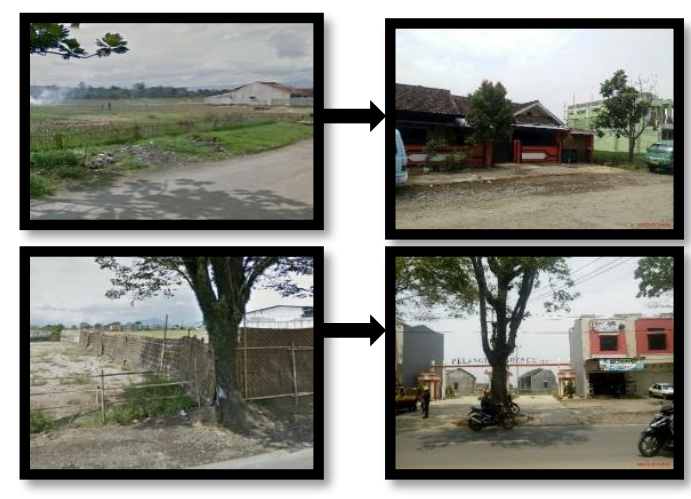

Gambar 1. Perubahan Fungsi Lahan di Kecamatan Ciparay

Sumber: Hasil Survey, 2018

\section{B. Landasan Teori}

Lokasi penelitian dipilih di Kecamatan Ciparay karena sektor pertanian di Ciparay merupakan salah satu lumbung padi di Kabupaten Bandung dan memiliki lahan pertanian yang subur sehingga kegiatan pertanian dapat berkembang.

Populasi dalam penelitian ini adalah jumlah penduduk yang menjual lahan pertanian yaitu sebanyak 29 orang. Karena subjeknya kurang dari 100, maka populasi langsung dijadikan sebagai sampel. Jadi jumlah sampel dalam penelitian ini berjumlah 29 orang.

Jenis data yang digunakan dalam penelitian ini adalah data primer dan data sekunder. Data primer adalah data yang diperoleh langsung dari responden sedangkan data sekunder yaitu data yang diperoleh secara tidak langsung dari responden dengan cara mengutip dari berbagai sumber tertentu.

Adapun metode yang digunakan adalah metode observasi, metode wawancara (interview), metode pencatatan dokumen. Data yang terkumpul selanjutnya akan dianalisis agar menjadi informasi yang bermakna terkait dengan masalah yang diteliti. Analisis yang digunakan pada permasalahan yaitu menggunakan analisis Uji beda rata-rata satu pihak

Hipotesis dalam uji beda rata-rata satu pihak ini menggunakan uji beda rata-rata untuk satu pihak yaitu pihak kanan. Uji ini ingin menguji bahwa purata (mean) tingkat pendapatan petani setelah adanya alih fungsi lahan lebih kecil dibandingkan dengan pendapatan sebelumnya. Secara manual rumus t-test yang digunakan untuk sampel berpasangan atau paired adalah sebagai berikut:

Menurut Sugiyono (2010), rumus uji t-test dependent, yaitu :

$\mathrm{H}_{0}$ :Pendapatan rata-rata petani adalah sama dengan sebelumnya

$\mathrm{H}_{1}$ :Pendapatan petani setelah adanya alih fungsi lahan lebih kecil

Pengujian Hipotesis:

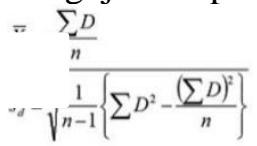

Keterangan :

$\mathrm{D}=$ selisih $\mathrm{xi}-\bar{x}$

$\mathrm{N} \quad=$ jumlah sampel

$\mathrm{x}$ bar $=$ Rata-rata

$\mathrm{Sd} \quad=$ standar deviasi dari $\mathrm{d}$

$$
\begin{aligned}
& \mathrm{HO}: \mu_{1}=\mu_{0} \\
& \mathrm{H} 1: \mu_{1}<\mu_{0}
\end{aligned}
$$

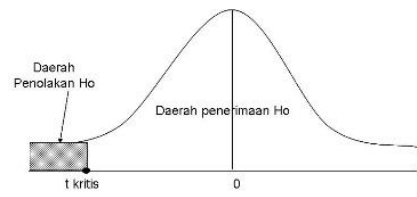

Riset Perencanaan Wilayah dan Kota 


\section{Hasil Penelitian dan Pembahasan}

Oleh karena luas lahan yang dimiliki petani pemilik berbeda-beda tidak bisa langsung semua di ambil rata-ratanya. Untuk memperoleh rata-rata pendapatan dari keseluruhan petani pemilik lahan semua luas lahan di ubah atau di konversi kedalam satuan Ha supaya semua luas lahan menjadi sama dalam $1 \mathrm{Ha}$

Tabel 1. Pendapatan Sebelum Alih Fungsi Lahan

\begin{tabular}{|c|c|c|c|}
\hline \multirow[b]{2}{*}{ No } & \multicolumn{3}{|c|}{ Pendapatan Sebelum } \\
\hline & Luas lahan $\mathbf{m}^{2}$ & Rp & $\mathrm{Rp} / \mathrm{Ha} / \mathrm{Bln}$ \\
\hline 1 & 200 & 1.050 .000 & 13.125 .000 \\
\hline 2 & 120 & 495.000 & 10.312 .500 \\
\hline 3 & 150 & 600.000 & 10.000 .000 \\
\hline 4 & 120 & 900.000 & 18.750 .000 \\
\hline 5 & 599 & 1.750 .000 & 7.303 .840 \\
\hline 6 & 419 & 1.500 .000 & 8.949 .881 \\
\hline 7 & 368 & 1.740 .000 & 11.820 .652 \\
\hline 8 & 85 & 245.000 & 7.205 .882 \\
\hline 9 & 370 & 580.000 & 3.918 .919 \\
\hline 10 & 155 & 300.000 & 4.838 .710 \\
\hline 11 & 380 & 1.300 .000 & 8.552 .632 \\
\hline 12 & 50 & 150.000 & 7.500 .000 \\
\hline 13 & 200 & 1.100 .000 & 13.750 .000 \\
\hline 14 & 100 & 1.800 .000 & 45.000 .000 \\
\hline 15 & 80 & 440.000 & 13.750 .000 \\
\hline 16 & 120 & 1.200 .000 & 25.000 .000 \\
\hline 17 & 124 & 1.260 .000 & 25.403 .226 \\
\hline 18 & 80 & 350.000 & 10.937 .500 \\
\hline 19 & 100 & 1.000 .000 & 25.000 .000 \\
\hline 20 & 100 & 900.000 & 22.500 .000 \\
\hline 21 & 63 & 200.000 & 7.936 .508 \\
\hline 22 & 100 & 950.000 & 23.750 .000 \\
\hline 23 & 80 & 230.000 & 7.187 .500 \\
\hline 24 & 150 & 1.200 .000 & 20.000 .000 \\
\hline 25 & 900 & 1.800 .000 & 5.000 .000 \\
\hline 26 & 900 & 2.000 .000 & 5.555 .556 \\
\hline 27 & 900 & 1.650 .000 & 4.583 .333 \\
\hline
\end{tabular}




\begin{tabular}{|c|r|r|rr|}
\hline \multirow{2}{*}{ No } & \multicolumn{3}{|c|}{ Pendapatan Sebelum } \\
\cline { 2 - 5 } & Luas lahan $\mathbf{~ m}^{\mathbf{2}}$ & \multicolumn{2}{c|}{ Rp } & \multicolumn{2}{c|}{ Rp/Ha/B/n } \\
\hline 28 & 920 & 2.100 .000 & 5.706 .522 \\
\hline 29 & 570 & 1.600 .000 & 7.017 .544 \\
& & & & \\
\hline & Total & 30.390 .000 & 380.355 .703 \\
\hline & Rata-rata & 759.750 & 9.508 .893 \\
\hline
\end{tabular}

Sumber: Hasil Pengolahan Kuisioner

Tabel 2. Pendapatan Setelah Alih Fungsi Lahan

\begin{tabular}{|c|c|c|c|}
\hline \multirow[b]{2}{*}{ No } & \multicolumn{3}{|c|}{ Pendapatan Setelah } \\
\hline & Luas lahan $\mathrm{m}^{2}$ & Rp & $\mathrm{Rp} / \mathrm{Ha} / \mathrm{Bln}$ \\
\hline 1 & 200 & 450.000 & 5.625 .000 \\
\hline 2 & 120 & 400.000 & 8.333 .333 \\
\hline 3 & 150 & 500.000 & 8.333 .333 \\
\hline 4 & 120 & 900.000 & 18.750 .000 \\
\hline 5 & 599 & 1.200 .000 & 5.008 .347 \\
\hline 6 & 419 & 650.000 & 3.878 .282 \\
\hline 7 & 368 & 500.000 & 3.396 .739 \\
\hline 8 & 85 & 300.000 & 8.823 .529 \\
\hline 9 & 370 & 350.000 & 2.364 .865 \\
\hline 10 & 155 & 400.000 & 6.451 .613 \\
\hline 11 & 380 & 950.000 & 6.250 .000 \\
\hline 12 & 50 & 500.000 & 25.000 .000 \\
\hline 13 & 200 & 600.000 & 7.500 .000 \\
\hline 14 & 100 & 700.000 & 17.500 .000 \\
\hline 15 & 80 & 250.000 & 7.812 .500 \\
\hline 16 & 120 & 1.000 .000 & 20.833 .333 \\
\hline 17 & 124 & 500.000 & 10.080 .645 \\
\hline 18 & 80 & 380.000 & 11.875 .000 \\
\hline 19 & 100 & 700.000 & 17.500 .000 \\
\hline 20 & 100 & 800.000 & 20.000 .000 \\
\hline 21 & 63 & 670.000 & 26.587 .302 \\
\hline 22 & 100 & 550.000 & 13.750 .000 \\
\hline 23 & 80 & 410.000 & 12.812 .500 \\
\hline 24 & 150 & 670.000 & 11.166 .667 \\
\hline
\end{tabular}




\begin{tabular}{|c|c|c|c|}
\hline \multirow[b]{2}{*}{ No } & \multicolumn{3}{|c|}{ Pendapatan Setelah } \\
\hline & Luas lahan $\mathbf{m}^{2}$ & $\mathbf{R p}$ & Rp/Ha/Bln \\
\hline 25 & 900 & 800.000 & 2.222 .222 \\
\hline 26 & 900 & 480.000 & 1.333 .333 \\
\hline 27 & 900 & 410.000 & 1.138 .889 \\
\hline 28 & 920 & 420.000 & 1.141 .304 \\
\hline 29 & 570 & 300.000 & 1.315 .789 \\
\hline & & 16.740 .000 & 286.784 .527 \\
\hline & rata & 577.241 & 7.169 .613 \\
\hline
\end{tabular}

Sumber: Hasil Pengolahan Kuisioner

Tabel 3. Nilai D

\begin{tabular}{|c|c|c|}
\hline No & $\mathrm{D}=\mathrm{xi}-\bar{X}$ & $D^{2}$ \\
\hline 1 & -1.544 .613 & 2.385 .829 .849 .558 \\
\hline 2 & 1.163 .720 & 1.354 .244 .615 .068 \\
\hline 3 & 1.163 .720 & 1.354 .244 .615 .068 \\
\hline 4 & 11.580 .387 & 134.105 .359 .097 .798 \\
\hline 5 & -2.161 .266 & 4.671 .070 .403 .263 \\
\hline 6 & -3.291 .332 & 10.832 .863 .362 .704 \\
\hline 7 & -3.772 .874 & 14.234 .578 .529 .711 \\
\hline 8 & 1.653 .916 & 2.735 .438 .929 .826 \\
\hline 9 & -4.804 .748 & 23.085 .606 .290 .071 \\
\hline 10 & -718.000 & 515.524 .385 .236 \\
\hline 11 & -919.613 & 845.688 .385 .188 \\
\hline 12 & 17.830 .387 & 317.922 .694 .454 .103 \\
\hline 13 & 330.387 & 109.155 .456 .449 \\
\hline 14 & 10.330 .387 & 106.716 .892 .026 .537 \\
\hline 15 & 642.887 & 413.303 .474 .264 \\
\hline 16 & 13.663 .720 & 186.697 .248 .661 .011 \\
\hline 17 & 2.911 .032 & 8.474 .107 .245 .608 \\
\hline 18 & 4.705 .387 & 22.140 .665 .205 .863 \\
\hline 19 & 10.330 .387 & 106.716 .892 .026 .537 \\
\hline 20 & 12.830 .387 & 164.618 .826 .169 .059 \\
\hline 21 & 19.417 .688 & 377.046 .623 .413 .326 \\
\hline
\end{tabular}




\begin{tabular}{|c|c|c|}
\hline No & $\mathrm{D}=\mathrm{xi}-\bar{X}$ & $\mathbf{D}^{2}$ \\
\hline 22 & 6.580 .387 & 43.301 .490 .812 .754 \\
\hline 23 & 5.642 .887 & 31.842 .171 .759 .308 \\
\hline 24 & 3.997 .053 & 15.976 .436 .643 .259 \\
\hline 25 & -4.947 .391 & 24.476.677.204.952 \\
\hline 26 & -5.836 .280 & 34.062 .162 .349 .339 \\
\hline 27 & -6.030 .724 & 36.369 .635 .372 .822 \\
\hline 28 & -6.028 .309 & 36.340 .507 .273 .532 \\
\hline 29 & -5.853 .824 & 34.267 .251 .885 .058 \\
\hline Total & 78.865 .745 & 1.743.613.189.897.270 \\
\hline Rata $^{2}$ & 1.971.644 & 43.590.329.747.432 \\
\hline
\end{tabular}

$$
\begin{aligned}
& S d=\sqrt{\frac{1}{28}\left\lfloor 1.743 .613 .189 .897 .270-\frac{(78.865 .745)^{2}}{29}\right\rfloor} \\
& S=\sqrt{54.612 .040 .382 .421} \\
& S=7.389 .996
\end{aligned}
$$

\section{T hitung}

$$
\begin{aligned}
& \mathrm{t}=\frac{X-\mu 0}{S d / \sqrt{n}} \\
& \mathrm{t}=\frac{7.169 .613-9.508 .893}{7.389 .996 / \sqrt{29}} \\
& \mathrm{t}=\frac{-2.339 .280}{137.228}=-17,04667
\end{aligned}
$$

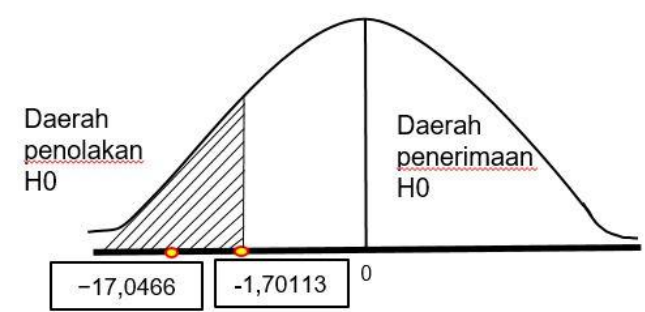

Gambar 2. kurva daerah penolakan dan penerimaan $\mathrm{H}_{0}$ Sumber : Hasil Analisis, 2019

\section{Uji signifikansi}

Diketahui $\mathrm{t}$ tabel $=-1,70113$, sehinga $\mathrm{T}$ hitung $-17,0466<\mathrm{T}$ tabel $-1,70113$ Sehingga dapat di simpulkan bahwa: H0 di tolak dan H1 di terima, artinya rata-rata Pendapatan petani yang menjual lahannya setelah adanya alih fungsi lahan di Kecamatan Ciparay, yaitu lebih kecil dari sebelumnya. Hal ini dikarenakan penghasilan yang di dapat dari hasil wirausaha tidak menentu dan memilki banyak saingan dengan yang lainnya. 


\section{Kesimpulan}

Dengan adanya alih fungsi lahan pertanian yang terjadi di Kecamatan Ciparay membuat banyak perubahan khususnya dalam sektor pertanian. Selain daripada luas lahan yang semakin berkurang tingkat pendapatan petani pun menjadi lebih kecil jika dibandingkan dengan sebelum adanya alih fungsi lahan, karena penghasilan yang di dapat dari hasil penjualan lahan pertanian tersebut digunakan untuk modal usaha baru , sedangkan dari hasil wirausaha sendiri hasil yang di peroleh tidak menentu dan memilki banyak saingan dengan yang lainnya. Selain itu kemampuan petani untuk mengelola uang hasil dari pernjualan lahan pertanian tersebut masih belum maksimal.

\section{Daftar Pustaka}

Arsyad, S. (1989). Korversi Tanah Dan Air. IPB. Bogor

Asyiawati, Yulia.2014. Strategi Pengendalian Pemanfaatan Lahan Sekitar Kawasan Kalimalang Kota Bekasi Secara Berkelanjutan. Jurnal PWK Volume 14, Nomor 1. Unisba. Bandung.

Azwar,Saifudin. 1998. Metode Penelitian,: Pustaka Pelaja. Yogyakarta

BPS. 2014 dan 2017. Kabupaten Bandung dalam Angka. Badan Pusat Statistik Provinsi Jawa Barat. Kabupaten Bandung.

http://www.academia.edu/6969472/Konversi_Lahan_Pertanian [diakses tanggal 13 Desember 2018]

Irawan, B., 2005, Konversi Lahan Sawah : Potensi Dampak, Pola Pemanfaatannya, dan Faktor Determinan, Forum Penelitian Agro Ekonomi Volume 23, Nomor 1, Juni 2005. Pusat Analisis Sosial Ekonomi dan Kebijakan Pertanian. Hal 8. Bogor.

Kamus Besar Bahasa Indonesia (2018). Dampak, [online]. Tersedia ;http;//kbbi.web.id/dampak. [5 januari 2019]

Lefiana, Elsa .2015 Identifikasi Keberadaan Mantan Pemilik Lahan Jalan Lingkar Utara Kabupaten Majalengka. Tugas Akhir,Prodi Perencanaan Wilayah dan Kota. Fakultas Teknik. Unversitas Islam Bandung. Bandung

Lestari, T. 2009. Dampak Konversi Lahan Pertanian Bagi Taraf Hidup Petani. Skripsi. Institut Pertanian Bogor. Bogor

Mosher A.T., 1966. Menggerakan dan Membangun Pertanian

Nasoetion dan Winoto, 1996. Masalah Alih Fungsi Lahan Pertanian dan Dampaknya Terhadap Keberlangsungan Swasembada Pangan. Dalam Prosiding Lokakarya : Persaingan Dalam Pemanfaatan Sumber Daya Lahan dan Air: Dampaknya terhadap Keberlanjutan Swasembada Beras. Hasil Kerjasama Pusat Penelitian. Jakarta

Pambudi, Andika. 2018. Analisis Nilai Ekonomi Lahan (Land Rent ) Pada Lahan dsn Permukiman di Kecamatan Ciampea. Kabupaten Bogor. Skripsi IPB. Bogor

Rahim, Dian A. 2007. Konversi Lahan Pertanian dan Dampaknya Terhadap Pelaku Konversi (Studi Kasus di Desa Tegalwaru dan Bojong Rangkas Kecamatan Ciampea). Tesis. Program Pascasarjana, Institut Pertanian Bogor.

Rauf, A.H., 2010. Alih Fungsi Lahan Pertanian Menjadi Lahan Perkebunan Tebu dan Dampaknya terhadap Masyarakat Pedesaan (Studi Kasus Perubahan Sosial Petani di Kecamatan Tolangohula Kabupaten Gorontalo). Disertasi, Gorontalo

Sitorus, Santun R.P. Evaluasi Sumberdaya Lahan. Tarsito. Bandung

Sudjana. 2013. Metode Statistika. Tarsito. Bandung

Sugiono. 2018. Metode Penelitian Kuantitatif. Alfabeta. Bandung

Suparmoko. 1989. Ekonomi Sumberdaya Alam dan Lingkungan: Suatu Pendekatan Teoritis. PAU-UGM. Yogyakarta. 